University of Wollongong

Research Online

Faculty of Informatics - Papers (Archive)

Faculty of Engineering and Information

Sciences

August 2007

\title{
A Service - Oriented Approach To Onshore Gas Transmission Pipeline Construction
}

\author{
L. Dunn \\ University of Wollongong, leone@uow.edu.au \\ P. Gibson \\ University of Wollongong, peterg@uow.edu.au
}

Follow this and additional works at: https://ro.uow.edu.au/infopapers

Part of the Physical Sciences and Mathematics Commons

\section{Recommended Citation}

Dunn, L. and Gibson, P.: A Service - Oriented Approach To Onshore Gas Transmission Pipeline Construction 2007.

https://ro.uow.edu.au/infopapers/618

Research Online is the open access institutional repository for the University of Wollongong. For further information contact the UOW Library: research-pubs@uow.edu.au 


\title{
A Service - Oriented Approach To Onshore Gas Transmission Pipeline Construction
}

\begin{abstract}
This research investigates whether a traditional manufacturing planning and control strategy would make Onshore Gas Transmission Pipeline Construction more competitive and if so, design the strategy. An indepth case study of Gas Transmission Pipeline Construction was carried out, along with an extensive literature review. The current pipeline construction process was analyzed from a strategic management perspective. From this perspective, it was found that the traditional 'make and sell' attitude of manufacturers has now almost entirely given way to a customer oriented 'sense and respond' service philosophy. This is compounded by the needs for waste avoidance, cost efficiency and service to the customer. This research investigates the strategic opportunities for establishing advantages over competitors by designing unique service oriented supply chain strategies. Rather than relying on functional hierarchy and command and control governance where a chain of commitments are poorly connected and difficult to reconfigure, the pipeline construction participants is challenged to develop more flexible process designs around a state of the art service based architecture. Complexity reduction has traditionally been used to deal with intricate construction supply chains. However, the architecture developed and demonstrated in this research will allow participants in pipeline construction to develop strategic opportunities around ideas of complexity absorption. The architecture is built on the premise that complexity absorption creates an organization that is strategically superior because it becomes a complex adaptive system that is unique to that organization. A case study is presented based on a major onshore gas transmission pipeline construction organization that illustrates an application consisting of Pipeline Construction Portal and Service Oriented Architecture. This model is internet-based and has three main constituents of Web Services, Portal and Client Services.
\end{abstract}

\section{Keywords}

Supply chain, strategy, service oriented, internet

\section{Disciplines}

Physical Sciences and Mathematics

\section{Publication Details}

This conference paper was originally published as Dunn, L, Gibson, P, A Service - Oriented Approach To Onshore Gas Transmission Pipeline Construction, IEEE/INFORMS International Conference on Service Operations and Logistics, and Informatics SOLI 2007, 27-29 Aug, 1-6. 


\title{
A Service - Oriented Approach To Onshore Gas Transmission Pipeline Construction
}

\author{
Dr. Leone Dunn and Associate Professor Peter Gibson
}

\begin{abstract}
This research investigates whether a traditional manufacturing planning and control strategy would make Onshore Gas Transmission Pipeline Construction more competitive and if so, design the strategy. An in-depth case study of Gas Transmission Pipeline Construction was carried out, along with an extensive literature review. The current pipeline construction process was analyzed from a strategic management perspective. From this perspective, it was found that the traditional 'make and sell' attitude of manufacturers has now almost entirely given way to a customer oriented 'sense and respond' service philosophy. This is compounded by the needs for waste avoidance, cost efficiency and service to the customer. This research investigates the strategic opportunities for establishing advantages over competitors by designing unique service oriented supply chain strategies. Rather than relying on functional hierarchy and command and control governance where a chain of commitments are poorly connected and difficult to reconfigure, the pipeline construction participants is challenged to develop more flexible process designs around a state of the art service based architecture. Complexity reduction has traditionally been used to deal with intricate construction supply chains. However, the architecture developed and demonstrated in this research will allow participants in pipeline construction to develop strategic opportunities around ideas of complexity absorption. The architecture is built on the premise that complexity absorption creates an organization that is strategically superior because it becomes a complex adaptive system that is unique to that organization. A case study is presented based on a major onshore gas transmission pipeline construction organization that illustrates an application consisting of Pipeline Construction Portal and Service Oriented Architecture. This model is internet-based and has three main constituents of Web Services, Portal and Client Services.
\end{abstract}

Index Terms - Supply chain, strategy, service oriented, internet

\section{INTRODUCTION}

This research is concerned with the improvement of strategic supply chain management systems in industrial engineering.

Leone Dunne is a Senior Lecturer in the Faculty of Informatics and Peter Gibson is Associate Professor in the Faculty of Engineering, both at University of Wollongong, Australia. leone@uow.edu.au \& peterg@uow.edu.au.
In particular, onshore gas transmission pipeline construction will be used as a major case study. Industrial engineering managers involved in large scale projects have traditionally relied on their own tacit knowledge and experience to manage supply processes. They draw on theories from project management to assist in the planning and control of major engineering projects, a typical example being the project management book of knowledge (PMBOK, 2003). Current production theory and practice are heavily influenced by the concepts and techniques of project management. According to the PMBOK[1] "a project is a temporary endeavour undertaken to produce a unique product or service." Any historical or strategic information relating to projects is usually stored only in the mind of the human project manager [2]. This focus on product uniqueness and the project form of organization has dominated thinking about production in AEC industries, so far as to discourage learning from non-project industries such as product and service manufacturing [3]. This had led to much research by (for example) the Lean Construction Institute at Berkley, California, where the focus has been on the engineering procurement process itself, with the introduction of lean production principles into the process. For example, [3]; [4], and others have studied large scale engineering projects as integrated lean supply chains. There is also a strong demand emerging in many engineering industries today for a more coherent strategy-based theory (see for example, work undertaken by the International Lean Construction Institute at Berkeley, California) and systems to support this theory.

\section{RESEARCH DESIGN}

The research used 'case study' as the main research strategy in investigating the planning and control process in onshore gas transmission pipeline construction. [12] defines "case study" as an empirical investigation into contemporary phenomenon operating in a real-life context. It is particularly valuable when there is not a clear delimitation between the phenomenon and the context itself'. Therefore, this research strategy is the most suitable because it incorporates all the normal uncertain conditions faced by practitioners [13][12]). This initial section gives a general view of the research design that shapes the contents of this paper. It describes the logic used for getting from the initial research questions to the conclusions. 
Firstly, it was necessary to establish an overall theory in order to set up a 'benchmark' for onshore gas transmission pipeline construction planning and control. A theoretical framework was initiated at the outset of the empirical work. The literature review supporting this theoretical framework covered initially operations management in general, with a particular focus on construction and manufacturing management from an intra-organizational perspective. The theoretical framework evolved (alongside the data collection as the observations of practice drove the researcher to bring it closer to the kind of problems encountered in construction practice today) into covering planning and control issues from an inter-organizational perspective, supply chain management and value stream analysis, and finally into studying the literature on the alignment of execution capabilities, including the planning and control requirements of the supply chains with the strategic positioning of the chains.

b. Industry conferences on Supply Chain Management strategies and execution were attended to gain a better understanding of the processes and issues discussed in the literature.

c. A pilot case study of onshore gas transmission pipeline construction was undertaken, which was regarded as the 'explanation building phase'. With this approach the researcher looks for evidence that matches the theory, in order to build an explanation of the facts [12]. The pilot case study was undertaken with Duke Energy International at Kembla Grange, NSW. A general description of the onshore gas transmission pipeline construction process was created, along with a study of present tools and technologies used in construction and the type of resources and information required by the contractors as well as a study of the contractor organizations and their roles in the construction process.

d. After initial data was collected in the pilot study, the research questions could be refined. An in-depth case study of onshore gas transmission pipeline construction was then carried out. The particular emphasis was on the planning and control of the construction process from an integrated supply chain perspective. From this case study, waste in the planning and control process could be identified. Further literature reviews and conference visits suggested that operational effectiveness by elimination of waste was not sufficient. The process had to be strategically aligned both within the organization, with strategic and tactical goals, as well as across organizations in the supply chain. For this purpose the case study then examined the overall strategic alignment of the construction process.

\section{DATA COLLECTION METHODS}

Executing a research strategy requires methods for data collection and analysis. The research methods available for case study, the research strategy adopted in this work were direct observation, documentary analysis, and interviews.
Observations: Due to the complexity of this research, observations were the first method used to gain data and develop a broad understanding of the organizations involved in the case study, and enabled the researchers to gain a high level view of the business process, and the interaction between suppliers and clients in that process.

Document Analysis: Within this research, document analysis was used to provide an in-depth insight into the process of pipeline construction, as well as the many documents required for monitoring and control of the construction process, such as the contracts, project planning documents, and many more. These documents were provided by Australian sub-contractor organizations involved in the gas transmission pipeline construction process and academics.

Semi-Structured Interview: This was the third and final method used to obtain richer and more complex data than simply using questionnaires [14]. This provided the interviewee the chance to introduce new topics. The interviews were conducted with various employees along each supply chain, gathering facts and perceptions relevant to the objectives of this research. They were used in conjunction with the observational studies to verify and gain a better understanding of the preceding results and to clarify any issues that arose previously. Interviews were conducted in person and by telephone.

\section{DATA ANALYSIS AND EVALUATION}

Three key concepts for data analysis and evaluation are the reliability, validity, and representativeness of the data.

Reliability: The majority of sources used for the study are widely used in pipeline construction. The interviews were conducted with very reliable and well respected members of the supply organizations. However, the researchers are aware that in pipeline construction there are few overall standards for terminology and definitions, including documents, and data.

Validity: The study was performed in a way that it was reliant on the sources used for the study that were available at the time the research was carried out. Also the terminology may change over time. The validity limitations of the study should be considered as an indicator to further investigation.

Representativeness: It is believed that the study itself is highly representative of not only onshore gas transmission pipeline construction in Australia, but also in the entire Asia-Pacific region. This is evidenced by the fact that many of the subcontractor organizations work in this region due to the thousands of kilometers of pipeline being constructed and the geographical location of these pipes eg the Eastern Gas Pipeline from New Guinea to Bass Straight.

\section{RESULTS OF THE CASE STUDY}

The following are a sample of some of operational shortcomings identified: 
Information Access, Knowledge Management and Organizational Learning: Lack of timely, in depth, and relevant information to pipeline partners appears to be one of the causes of collaboration and control problems in pipeline construction. Information is fragmented and only hard copy information or scanned information is available and sometimes word-of-mouth only. Knowledge management is fragmented and out of date, and shared only on a limited basis. Knowledge is also restricted to single projects and phases. Knowledge gained by one design team for one project is not always recorded or passed on to designers from other projects. Experience gained on one project is not transferable to other projects, unless the same project manager is employed. There is at present no facility for a lessons learned (project history) database to be accessed by subcontractor organizations. Learning is shared mostly at conferences and seminars and occurs sporadically. There is also little allowance for multilingual or multicultural aspects of information exchange. Information when available on the Internet is not selective by role or viewing device, resulting in too much or not enough information being communicated. Information is not personalized by role or viewing device, such as pocket PCs. There is no one point of access for all information from the various systems involved in pipeline construction.

Collaboration and Communication: Management teams and subcontractor organizations do not have the basic tools to collaborate with peers, regional management, and corporate offices. At present information and communication is largely by hard copy. This prevents development of a work environment that is open, and supports the breaking down of cultural barriers. There is no efficient means of viewing and communicating what needs to be achieved among off- and on-site personnel. There is also no efficient way of sharing information and collaborating with head office or site office in real time.

Workforce and Relationship Management: The pipeline workforce could be considered to be made up of the needs of management and the needs of the individuals but these are not distinguishable in the present system. At present, decisions are made sequentially by specialists and 'thrown over the wall'. There is no involvement of downstream players (supply chain partners) in upstream decisions. There is a limited awareness and understanding of IT/Internet and its potential benefits to the project. This leads to misunderstandings and distrust between supply partners. The lack of inclusion of all participants in pipeline construction decisions leads to an arms length and often adversarial culture among the subcontractor organizations. This could lead to high turnover rates and unavailability of qualified personnel. Presently training is not provided on the job and is regarded as secondary because time away from work is costly. Current performance management systems are either paper based or standalone desktop PCs. This also has to do with information access. At present there is no facility where participants can view or update information from the field in a real time manner. From a human resource perspective there is no real time access to employees' credentials and qualifications, suggestions, grievances, time sheets and so on.

Design: The present approach to product and process design is fragmented. The product design is outside of the project lifecycle and if drawings need to be accessed or changed during the construction process, this requires a long wait. There is no focus on concurrency of design, process, and supply chain. All product lifecycle stages should be considered in design to avoid downstream errors. There is no link between the supply chain design and the product design. If concurrency were considered, sourcing would be design-build. As it is, decisions about sourcing contracts are made separately from the product (and process) design.

Materials and Inventory Management: Because there are only manual processes or desktop systems used, there is a lack of visibility of stock flow, a lack of integration with maintenance and equipment service management, and equipment tracking. Participants build up large inventories to protect their own interests. There is a lot of surplus at the end of the project, which the project manager must sell or take to a new site. As mentioned elsewhere [15], the 'built to order' pipeline requires a spontaneous supply chain with spontaneous inventory management, but there is a lack of focus on automatic restocking, for example, by using autonomic logistics There is no automatic integration with other systems, such as General Ledger, Accounts Payable, Purchase Order, Job Costing, and Equipment Control.

Supply Chain Management: Supply chains are treated as separate organizations linked together through the market. They are fragmented, with limited communication between disciplines within a phase and between phases. In some cases strategic alliance relationships between the primary supplier (contractor or consultant) and sub-suppliers based on preestablished relationships and experiences exist. The intent is to continue a working relationship. Electronic sourcing and procurement is not realized to its full potential. For example, the downloading and printing of tendering documents for estimating purposes; electronic funds transfer is not being used.

Project and Portfolio Management: The monitoring and control of all information relating to the project in an up to date manner is not possible using manual procedures, or limited desktop PC facilities. There is no central one point of access integrated way of enquiring and reporting on project progress. There needs to be a way of enquiring about contract status from different viewpoints, such as customer, project manager, contractors, or combinations of the above. There is no means 
to view contract value, billings to date, cost to date, variance, forecasted costs to complete, percentage completion and projected profit. This is because there is no integration with financial management systems.

The above discussion of the 'pain points' (shortcomings) identified across the pipeline project requires strategic capabilities supported by a mobile internet platform. Following is a summary of the current factors limiting strategic advantage and the strategic capabilities enabled by integration of Internet technology.

\section{SUSTAINABLE COMPETITIVE ADVANTAGE THROUGH INTERNET DRIVEN SUPPLY CHAIN}

The Internet enables sustainable competitive advantage through the innovation of business processes and concepts. This innovation comes about by leveraging the organization's dynamic capabilities. The tables below consider only a sample of the issues to be considered in the design of a 'competitive' supply chain. The following tables are extracts from the results of the investigation that illustrate the main factors limiting strategic advantage in comparison to the strategic capabilities enabled by the internet. (Space does not allow the full detail of the investigation to be reported here.)

Several design solution alternatives were considered. What is required is an open and robust technology framework that enables a 'to-order' construction environment. The proposed solution enables an on demand construction environment. Its purpose is to bring the business (systems, information, and knowledge) to the people who need it and in a form that is usable within the context of the work, or business process, they are performing. In so doing, it creates a cumulative benefit for all members

\section{KEY FEATURES OF THE TO-ORDER ENVIRONMENT}

The following section describes model and architecture recommended for the 'to - order' (sense and respond) large engineering project environment. The focus here is on a description of the conceptual architectures of the system. The proposal below is for a gas pipeline portal and service oriented architecture, which will integrate planning, design, delivery, and maintenance.

Role-based Partner Portal: A role based partner portal is proposed that allows one point of access to all systems. Here, all employees access knowledge and systems needed for their work. This model highlights the pipeline management team roles, but other roles can participate in and use the portal as required. The portal provides secure access to all of the components in the system. The actual component functions presented will vary based on the defined role of the individual seeking access. The portal determines and adjusts the format of content to suit the characteristics of the user interface (device) being used during the session. To allow for location of critical information or knowledge, the portal supports a search function across all pipeline enterprise content. The portal also manages and coordinates the delivery of alerts that are generated by other systems. The portal enables companies to streamline their workflow by capturing payroll, equipment usage, material costs, and hired equipment data at the source, and update their corporate systems without the re-keying of data. This data is then transferred to the company server using wireless Internet access.

Service Oriented Architecture: This research is proposing that all capabilities - design, plan, deliver, maintain - as an ecology of e-business services. 'Ecology' means that the construction process becomes a service provider to other organizations, but also a service broker and a service requestor. What is presently manual will become Internet based as a service, not simply as a transaction. The services will be implemented as web services. The term architecture is widely understood and used for what it is--a top-down description of the structure of the system[16]. Service-oriented architecture presents an approach for building distributed systems that delivers application functionality as services to either end-user applications or other services. It is comprised of elements that can be categorized into functional and quality of service, as illustrated below [17]:

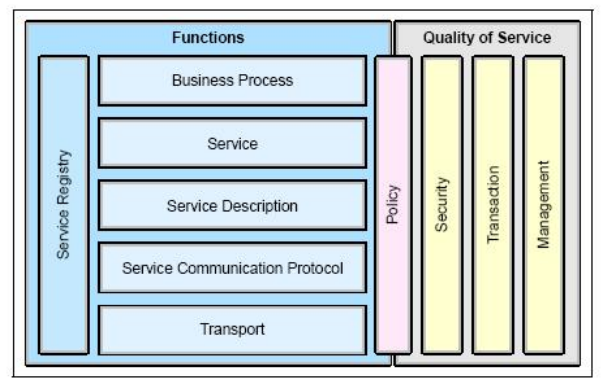

Figure 1: Elements of a Service Oriented Architecture [17]

\section{SERVICE -ORIENTED ARCHITECTURE AND WEB PORTAL}

The above discussion described the advantages of a web services and portal architecture for gas transmission pipeline construction. $\mathrm{n}$ the pipeline model as illustrated in Figure 2, below where most transactions are manual and isolated. 


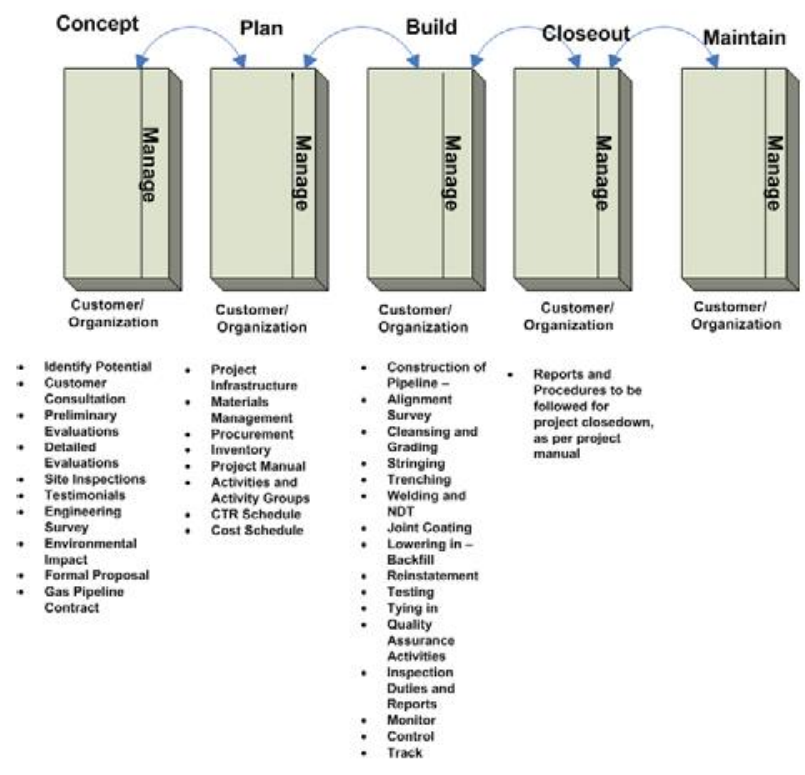

Figure 2: As Is Gas Transmission Pipeline Construction Business Architecture

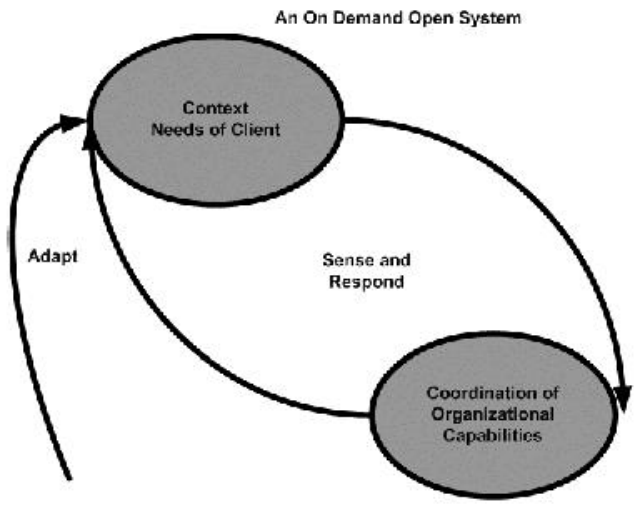

Figure 3: A Dynamic Needs/Capabilities Model [adapted from [18]].

Instead of a linear over the wall management approach as depicted in Figure 2, the integrated architecture would be in the form of an adaptive sense and respond sy stem, as represented by the needscapabilities management model shown in Figure 3:

This model is dynamic and based on the notion of manufacturing as a sense and respond business, rather than a make and sell business.
The business processes will be offered in the form of ebusiness services (with or without facilitating goods) such as:

Planning Services

Inspection Services

Survey Services

Evaluation Services

Contract Writing Services

Materials and Inventory Management Services

Procurement Services

Tendering Services

Bidding Services

Welding Services

Design Services

Hydrostatic Testing Services

Financial and Accounting Services

Each of these services would have an operational strategy, an IT component, as well as a physical product component. Where required a composite web service and workflow could be utilized as illustrated in Figure 4, which shows part of a design service example:

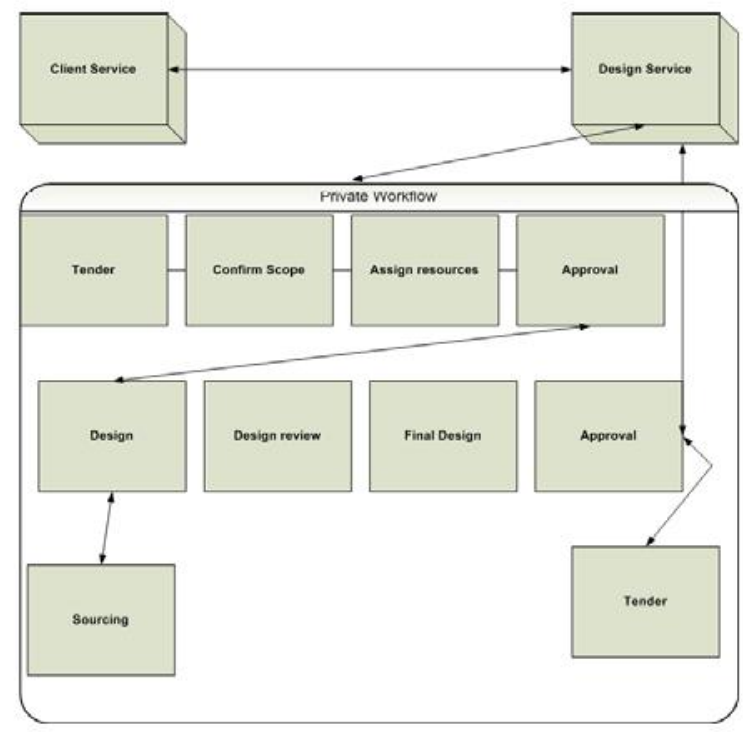

Figure 4: A Suggested Design Web Service For Pipeline Construction With Private Workflow

Finally, Figure 5 gives an overview of the portal and service oriented architecture proposed. 


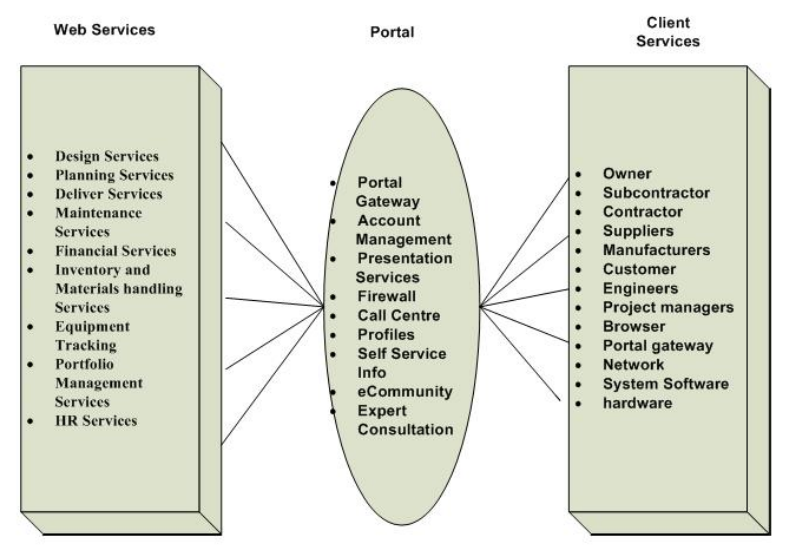

Figure 5: Proposed Pipeline Construction Portal and SOA

\section{CONCLUSION}

This paper has argued that recent developments in manufacturing philosophy will provide a benefit for large project engineering industries. This research has proposed that those industries work towards competitively superior Internet-based service oriented strategies that are able to embrace complexity, rather than the traditional Tayloristic industrial engineering strategies that have become the norm. This paper has also proposed a model to implement such strategy. This will provide a means of building dynamic capabilities in the organization to create a learning organization. Organizations that develop capabilities to participate in supply chains that achieve these processes will become more innovative, leading to sustainable competitive advantage.

By adopting an adaptive project-based business process, processes are dynamic and re-configurable to suit the requirements of the customer order. This work has proposed an appropriate operations strategy and tactical IT system to support this adaptive process. A management model that is being proposed is a needs-capabilities model. This model is dynamic and based on the notion of 'sense and respond' rather than a 'make and sell'. The operations strategy proposed here and architecture map easily to this model, and provide strategic opportunities for innovative players in large engineering project businesses.

\section{REFERENCES}

[1] Project Management Book of Knowledge (PMBOK), Project Management Institute (2003)

[2] Neto, J. de P.B. (2002) "The Relationship Between Strategy And Lean Construction", Proceedings IGLC-10, Gramado, Brazil.

[3] Koskela, L. (2004) "Moving on - beyond lean thinking", Lean Construction Journal 2004 1(1): 24-32.
[4] Ballard, G. (2000) The Last Planner System of Production Control PhD Research, School of Civil Engineering Faculty of Engineering The University of Birmingham May.

[5] Sterman, J. D. (1992) System Dynamics Modelling for Project Management, http://web.int.edu/jsterman/www/SDG/project.pdf

[6] Mason-Jones, R, Towill, D.R. (1998) "Shrinking the Supply Chain Uncertainty Circle", IOM Control, 24(7), pp.17-22.

[7] Womack, J., Jones, D., Roos, D. (1990) The Machine That Changed the World, Macmillan, New York, NY

[8] Porter, M. (1985) Competitive Advantage Creating and Sustaining Superior Performance. Free Press, New York.

[9] Gaither, N. and Frazier, G. (2002) Operations Management 9th Edition South-Western, Thomson Learning, US.

[10] Hagel III, J. and Brown, J.S. (2003) The Agile Dance of Architectures - Reframing IT Enabled Business Opportunities, SAP Design Guild, Edition on Composite Applications

[11] Hamel, G. (2000) Leading The Revolution, Boston: Harvard Business School Press.

[12] Yin, R.K. (1994). Case Study Research: Design and Methods, 2nd edition, Applied Social Research Method Series, 5, Sage Publications, Beverly Hills, CA.

[13] Robson, C. (1993) Real World Research: a Resource for Social Scientists and Practitioner Researchers. Blakewell, Cambridge, US

[14] Cavana, R.Y., Sekaran, U, and Delahaye, B. L. (2001) Applied Business Research: Qualitative and Quantitative Methods, John Wiley and Sons Ltd, Australia.

[15] Anderson, D.L. (2004). "Special Interview: Achieving Supply Chain Excellence Through Technology", http://www.ascet.com/documents.asp?d_ID $=2507$

[16] Rechtin, E. (1991). Systems Architecting: Creating and building complex systems, Prentice-Hall.

[17] Ganci, J. (2001) Patterns: SOA Client-Access Integration Solutions, IBM Redbooks

[18] Haeckel, S.H. 2004. Becoming a Sense and Respond Organization. IBM Netherlands Captain's Council Presentation, October 2004 